\title{
Additional records of metazoan parasites from Caribbean marine mammals, including genetically identified anisakid nematodes
}

\author{
Marlene M. Colón-Llavina • Antonio A. Mignucci-Giannoni • Simonetta Mattiucci • \\ Michela Paoletti • Giuseppe Nascetti • Ernest H. Williams Jr.
}

Received: 3 January 2009/Accepted: 18 June 2009/Published online: 7 July 2009

(C) Springer-Verlag 2009

\begin{abstract}
Studies of marine mammal parasites in the Caribbean are scarce. An assessment for marine mammal endo- and ectoparasites from Puerto Rico and the Virgin Islands, but extending to other areas of the Caribbean, was conducted between 1989 and 1994. The present study complements the latter and enhances identification of anisakid nematodes using molecular markers. Parasites were collected from 59 carcasses of stranded cetaceans and manatees from 1994 to 2006, including Globicephala macrorhynchus, Kogia breviceps, Kogia sima, Lagenodelphis hosei, Mesoplodon densirostris, Peponocephala electra, Stenella longirostris, Steno bredanensis, Trichechus manatus. Tursiops truncatus, and Ziphius cavirostris. Sixteen species of endoparasitic helminthes were morphologically identified, including two species of acanthocephalans (Bolbosoma capitatum, Bolbosoma vasculosum), nine
\end{abstract}

M. M. Colón-Llavina • E. H. Williams Jr.

Department of Marine Sciences, University of Puerto Rico, P.O. Box 9000, Mayagüez 00680, Puerto Rico

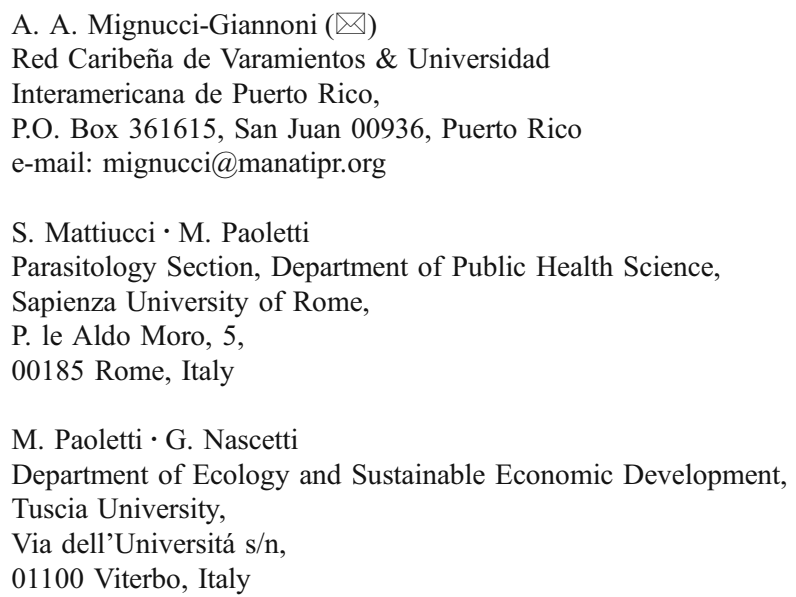

species of nematodes (Anisakis sp., Anisakis brevispiculata, Anisakis paggiae, Anisakis simplex, Anisakis typica, Anisakis ziphidarium, Crassicauda anthonyi, Heterocheilus tunicatus, Pseudoterranova ceticola), two species of cestodes (Monorygma grimaldi, Phyllobothrium delphini), and three species of trematodes (Chiorchis groschafti, Pulmonicola cochleotrema, Monoligerum blairi). The nematodes belonging to the genus Anisakis recovered in some stranded animals were genetically identified to species level based on their sequence analysis of mitochondrial DNA (629 bp of mtDNA cox 2). A total of five new host records and six new geographic records are presented.

\section{Introduction}

Marine mammals are parasitized by a variety of helminthes, including acanthocephalans, cestodes, nematodes, and digeneans (Dierauf 1990; Aznar et al. 2001). Some of them cause diseases but rarely death of the host (Raga et al. 1997; Dailey 2001). In the Caribbean, studies concerning marine mammal parasites are scarce. Prior to the mid1990s, only Arnold and Gaskin (1975), Morales-Vela and Olivera-Gómez (1993), and Debrot and Barros (1994) reported finding endoparasites in cetaceans from the area. Mignucci-Giannoni et al. (1998) conducted the most comprehensive study of the metazoan parasitic fauna of cetaceans in the Caribbean followed by an assessment of the endoparasites of the West Indian manatee (Trichechus manatus) in Puerto Rico (Mignucci-Giannoni et al. 1999a) and the Dominican Republic (Mignucci-Giannoni et al. 1999b). Mora-Pinto (2000) studied the morphological differences between trematodes found in the manatee's intestine. Cintrón-de Jesús et al. (Cintrón-de Jesús 2001; Cintrón-de Jesús et al. 1999, 2005) identified the barnacles 